
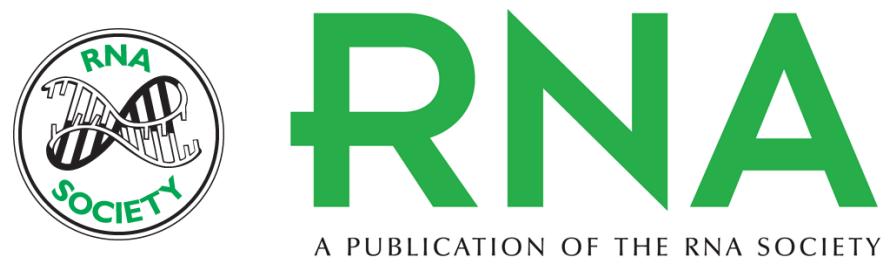

\title{
Dissecting FMR1, the protein responsible for fragile $X$ syndrome, in its structural and functional domains.
}

S Adinolfi, C Bagni, G Musco, et al.

RNA 1999 5: 1248-1258

References Article cited in:

http://rnajournal.cshlp.org/content/5/9/1248\#related-urls

Email alerting Receive free email alerts when new articles cite this article - sign up in the box at the service top right corner of the article or click here

To subscribe to RNA go to:

http://rnajournal.cshlp.org/subscriptions 


\title{
Dissecting FMR1, the protein responsible for fragile $X$ syndrome, in its structural and functional domains
}

\author{
SALVATORE ADINOLFI, ${ }^{1}$ CLAUDIA BAGNI, ${ }^{2}$ GIOVANNA MUSCO,${ }^{1}$ TOBY GIBSON, ${ }^{3}$ \\ LELIO MAZZARELLA, ${ }^{4}$ and ANNALISA PASTORE ${ }^{1}$ \\ ${ }^{1}$ The National Institute for Medical Research, The Ridgeway, Mill Hill, London NW7 1AA, United Kingdom \\ ${ }^{2}$ Dipartimento di Biologia, via della Ricerca Scientifica, Tor Vergata, Italy \\ ${ }^{3}$ European Molecular Biology Laboratory, Meyerhofstr. 1, D-69012 Heidelberg, Germany \\ ${ }^{4}$ Dipartimento di Chimica, via Mezzocannone 4, I-80134 Napoli, Italy
}

\begin{abstract}
FMR1 is an RNA-binding protein that is either absent or mutated in patients affected by the fragile $X$ syndrome, the most common inherited cause of mental retardation in humans. Sequence analysis of the FMR1 protein has suggested that RNA binding is related to the presence of two K-homologous $(\mathrm{KH})$ modules and an RGG box. However, no attempt has been so far made to map the RNA-binding sites along the protein sequence and to identify possible differential RNA-sequence specificity. In the present article, we describe work done to dissect FMR1 into regions with structurally and functionally distinct properties. A semirational approach was followed to identify four regions: an $\mathrm{N}$-terminal stretch of 200 amino acids, the two $\mathrm{KH}$ regions, and a C-terminal stretch. Each region was produced as a recombinant protein, purified, and probed for its state of folding by spectroscopical techniques. Circular dichroism and NMR spectra of the $\mathrm{N}$-terminus show formation of secondary structure with a strong tendency to aggregate. Of the two homologous KH motifs, only the first one is folded whereas the second remains unfolded even when it is extended both $\mathrm{N}$ - and $\mathrm{C}$-terminally. The $\mathrm{C}$-terminus is, as expected from its amino acid composition, nonglobular. Binding assays were then performed using the 4-nt homopolymers. Our results show that only the first $\mathrm{KH}$ domain but not the second binds to RNA, and provide the first direct evidence for RNA binding of both the N-terminal and the $\mathrm{C}$-terminal regions. RNA binding for the $\mathrm{N}$-terminus could not be predicted from sequence analysis because no known RNA-binding motif is identifiable in this region. Different sequence specificity was observed for the fragments: both the N-terminus of the protein and KH1 bind preferentially to poly-(rG). The C-terminal region, which contains the RGG box, is nonspecific, as it recognizes the bases with comparable affinity. We therefore conclude that FMR1 is a protein with multiple sites of interaction with RNA: sequence specificity is most likely achieved by the whole block that comprises the first $\approx 400$ residues, whereas the $\mathrm{C}$-terminus provides a nonspecific binding surface.
\end{abstract}

Keywords: FMR1; fragile sites; fragile X; modular proteins; RNA-binding proteins

\section{INTRODUCTION}

Progress in gene mapping technology has recently allowed identification of several genes involved in human genetic diseases and of the proteins encoded by them. This information has opened new avenues for approaching hereditary disorders at a molecular level and correlating their genetics with a more thorough understanding of the biochemical mechanisms that dictate the dysfunctions. One such genetic disease, with a huge impact on the world population, is the fragile $X$

Reprint requests to: Annalisa Pastore, The National Institute for Medical Research, The Ridgeway, Mill Hill, London NW7 1AA, United Kingdom; e-mail: apastor@nimr.mrc.ac.uk. syndrome (Hagerman, 1991). This syndrome is an X chromosome-linked dominant disorder and the most frequent cause of inherited mental retardation in humans. The incidence is approximately 1 case in 4,000 males and 1 in 7,000 females (Imbert et al., 1998). The disease is characterized by mental retardation of variable severity, autistic behavior, macroorchidism in adult males, characteristic facial deformity and hyperextensible joints (Hagerman, 1991). At the molecular level, the gene responsible for the disease has been located at the Xq27.3 locus (Verkerk et al., 1991). Appearance of the syndrome correlates with the presence in the FMR1 gene of a large trinucleotide expansion (CGG) and with hypermethylation of a $\mathrm{CpG}$ island within the promoter region (Mandel \& Heitz, 1992). The length of 
the trinucleotide expansion correlates with clinical severity of the effect.

In normal individuals, the FMR1 gene encodes an RNA-binding protein, FMR1 (Siomi et al., 1993a). The protein is absent or mutated in patients affected by the syndrome (Pieretti et al., 1991; Imbert et al. 1998). Although the full-length FMR1 protein is a 632-aminoacid protein, several shorter forms have been observed in vivo as a result of alternative splicing of several of the 17 exons present in the gene (Verkerk et al., 1993). Despite several attempts to identify the function of FMR1 in the cell, still far too little is known about this protein, thereby preventing a more thorough understanding of its role in the fragile $X$ syndrome.

It is known that FMR1 is expressed in many tissues, particularly in the brain and in testes, the major organs affected in the fragile X syndrome (Abitbol et al., 1993). The protein is usually localized mainly in the cytoplasm, but nuclear localization is observed for isoforms lacking exon 14 (Devys et al., 1993; Eberhart et al., 1996; Sittler et al., 1996; Bardoni et al., 1997). RNAbinding properties of FMR1 and the two homologs FXR1 and FXR2 have been demonstrated with synthetic RNA homopolymers, as no in vivo RNA target has yet been identified (Siomi et al., 1993a, 1995). It has also been shown that all proteins of the FMR family can be associated with translating polysomes in the form of messenger ribonuclear particles (mRNP) (Corbin et al., 1997; Feng et al., 1997).

Sequence analysis of the FMR family shows the presence of three potential RNA-binding domains: an RGG motif and two K-homologous $(\mathrm{KH})$ modules (Siomi et al., 1993a, 1995) (Fig. 1). The KH module is an evolutionarily conserved sequence motif of about 70 amino acids (Gibson et al., 1993). It is present in single or multiple copies in a wide variety of quite diverse proteins that all work in close association with RNA. Because the presence of the $\mathrm{KH}$ motif is the only common sequence similarity among these proteins, it was suggested that the domain itself is the region responsible for RNA binding (Gibson et al., 1993). Considerable evidence has now been accumulated in support of this hypothesis (Leffers et al., 1995; Urlaub et al., 1995; Dejgaard \& Leffers, 1996; Kanamori et al., 1998; Yang et al., 1998). Among other things, it was shown that an

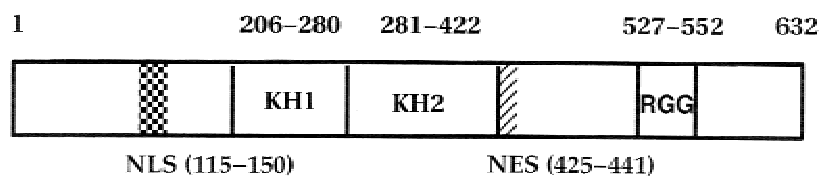

FIGURE 1. Schematic representation of the FMR1 protein with the position of the three putative RNA-binding motifs $(\mathrm{KH} 1, \mathrm{KH} 2$, and RGG box). The nuclear localization signal (NLS) and nuclear export signal (NES) are also indicated. The domain boundaries of the two $\mathrm{KH}$ domains are indicated as proposed in Musco et al. (1996) and supported by data presented in this article.
Ile304 $\langle$ MDRV $\rangle \rightarrow$ Asn missense mutation in the second FMR1 $\mathrm{KH}$, identified in a severe fragile $X$ syndrome patient, partially impairs RNA binding in vitro (De Boulle et al., 1993; Siomi et al., 1994; Feng et al., 1997; Brown et al., 1998). A nuclear export signal (NES) and a nuclear localization signal (NLS) were identified in the region of the protein encoded by exon 14 and in the $\mathrm{N}$-terminus, respectively (Eberhart et al., 1996; Fridell et al., 1996; Bardoni et al., 1997).

One of the fundamental questions that at this point is worth addressing is which region(s) of the protein interact(s) with RNA and whether they have sequence specificity in the binding. We report here an exhaustive study of the binding properties of FMR1 with the four homonucleotides. To map the sites of interactions and the contribution to the binding of the different regions along the sequence, we have produced recombinant versions of FMR1 fragments. The sequences of these deletion mutants were selected according to a semirational approach: the fragment boundaries were first selected according to recognition of conserved regions or modules in a multiple alignment of the FMR family. The state of fold of each fragment, that is whether or not they are able to adopt a tertiary fold and therefore form structurally independent units (domains), was then tested by suitable biophysical techniques. This point is essential in any study using deletion mutants for correct interpretation of functional assays, as it is the only way to discriminate between a functional rather than structural role of a given region of a protein. Finally, the fragments were probed in a band-shift assay for their binding properties and specificities. Full account of our results is given in the following sections.

\section{RESULTS}

\section{Can FMR1 be expected to fold into distinct structural domains? A sequence analysis}

Analysis of the multiple sequence alignment (Fig. 2A) carried out on the complete sequence of human FMR1 with related proteins from vertebrate shows high degree of conservation. A strongly conserved block of approximately 450 amino acids is observed that goes from the $\mathrm{N}$-terminus to the end of the sequence encoded in exon 14 (residue 444 in Fig. 2A). Within this region, the first 214 amino acids form a conserved stretch, delimited on one side by the $\mathrm{N}$-terminus and on the other side by the beginning of the first $\mathrm{KH}$ domain $(\mathrm{KH} 1)$, as identified by previous multiple alignments and by structure determination (Musco et al., 1996, 1997). This region designated FNT (FMR1 N-terminal domain) shows $70-80 \%$ identity and $80-90 \%$ similarity within the family and contains an amino acid distribution typical of globular domains (Creighton, 1993).

Several positively charged groups are present and conserved along the sequence. A secondary structure 
A

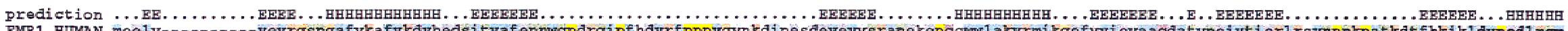

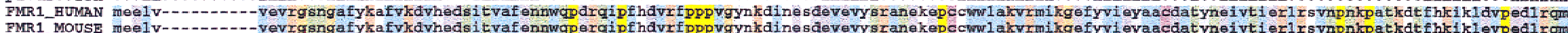

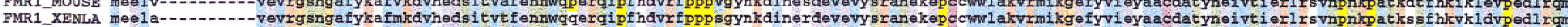

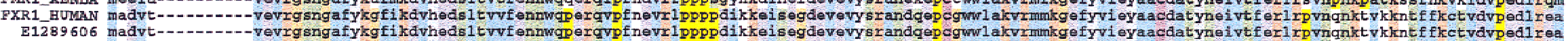

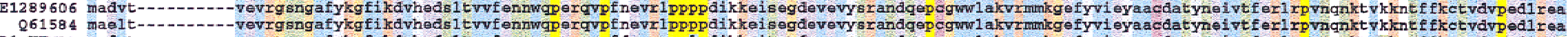
FXR1_XENLA medmt--

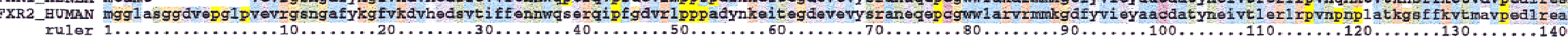

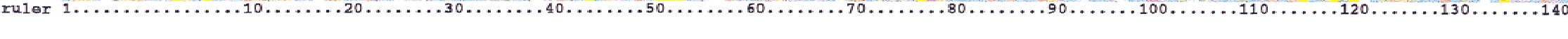

pređiction Hн. .

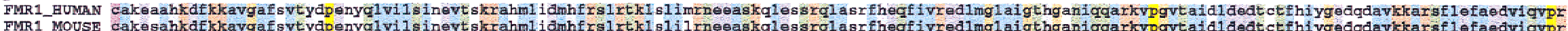

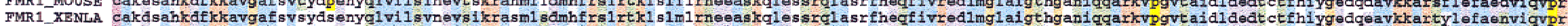

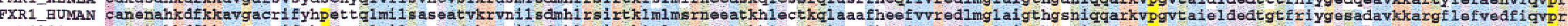
1289606 canenahkdfkkavgacrifyhpettglmil saseatvkrvnil sdmhlrsirtk1mlmsmeeatkhlectkq1aaafheefvvredlmglaigthgsniggarkvpgvtaieldedtgtf ri ygesaeavkkargfmefvedfiqvpr

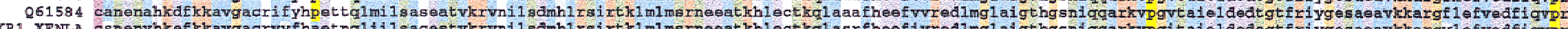

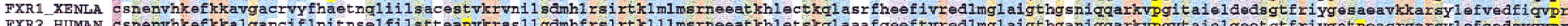

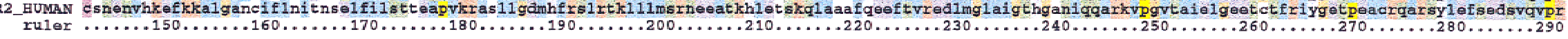

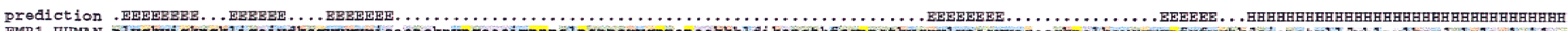

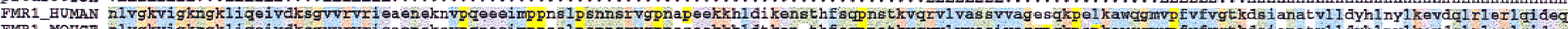

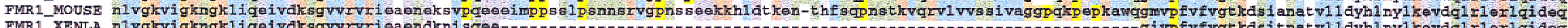
FMR1_XENLA n1 Vgkvigkngkliqeivdksgvvrvrieaendknisqee--E1289606 nivgkvigkngkvigeivaksgvvIvxiegdnenk1 pred--.-.061584 nivgkvigkngkviqeivdksgvvrvilegdnenk1pred---

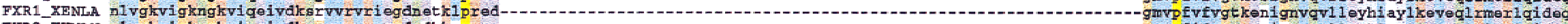

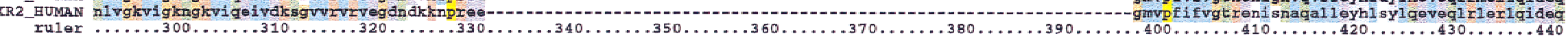

prediction $\mathrm{HH} H \mathrm{H}$. .

FMR1_HUMAN 1rqigassrpppn--.-rtakeksyvtadgqgmg-rgsxpyr-..n FVR1_MOUSE 1rqigassrpppn----rtakekgyvtddgqgmg-rgsxpyr----nrghgrr--gpgy--tsgtnseasnasetesdhrdel saws1apteeeres-flrrgdgrrrrgggrggg---grgrggg-----------fkgndahsr--tân

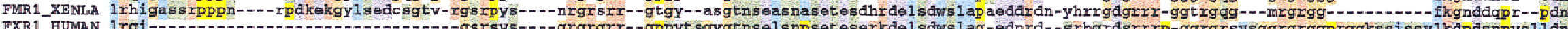
KR1_HUMAN 1rq1---12. 0615841 1rqi--FXR1_XENLA 1rqigmg frpsss---rgtekekgyatdestassvrgsrsys----grgrgrx--gpnytsgygtnsel snpseteserkeel satwslag-edere--srqqrdsrrrp-ggrgrsgsagrgrggsrggks issv1kdpdsnpys11dn

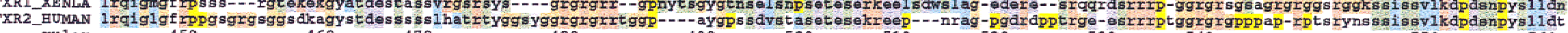

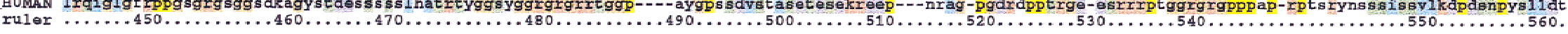

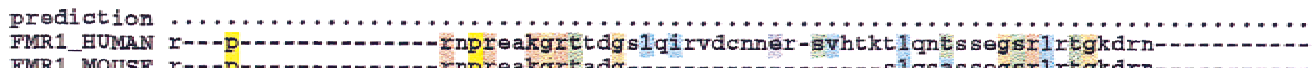

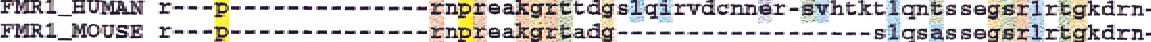

FXR1_HUNLA

1_HOMAN tesdqtadtaaseshhstnrrrrsrrrrtdedavimagmtesdtasvnenglvtvadyisraesqsrqr--nlpretlaknk:$\ldots \ldots \ldots \ldots \ldots \ldots \ldots \ldots \ldots \ldots \ldots \ldots \ldots \ldots \ldots \ldots$
nlpretlaknkk-0. FXR1_XENLA tesdqtadtdaseshhntnrrrrsrrrrtdedss1mdgmteldnasvneng1vtvadyisraesqsigr--n1pket1akgkK-

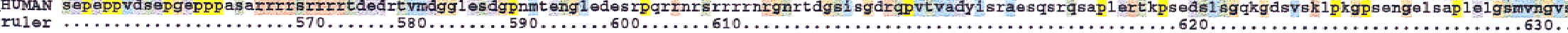

FIGURE 2. (Figure continues on facing page.) 


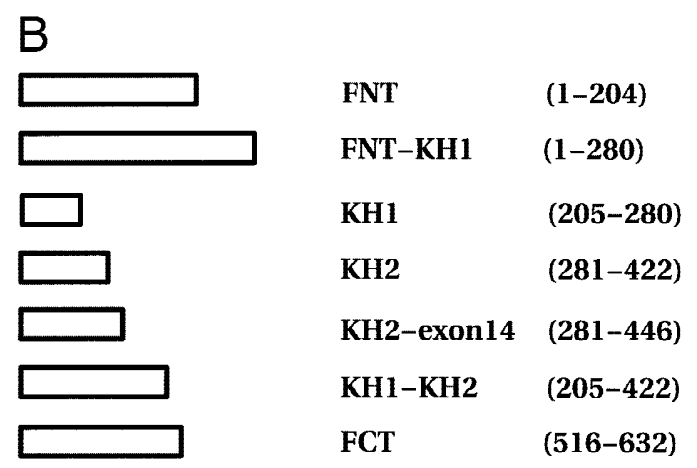

FIGURE 2. A: Multiple alignment of the FMR family, color-coded to highlight similarities. All G (orange) and $\mathrm{P}$ (yellow) residues are colored. Other coloring is by conserved property in more than $40 \%$ (or more than $30 \%$ for $\mathrm{K}, \mathrm{R}, \mathrm{H}$ ) of a column according to the following convention: Blue, hydrophobic; light blue, partially hydrophobic; red and pink, positive; purple, negative; green, hydrophilic. The proteins are identified by their Swiss-Prot entry names. The secondary structure prediction as obtained by the PHD server (prediction) is displayed in the first line. The sequence numbering (ruler) is displayed according to the FMR1 HUMAN sequence. B: Schematic diagram summarizing the constructs used in the present study. Each fragment is indicated with a rectangle. The numbers refer to the amino acid sequence of the Swiss-Prot FMR1_HUMAN entry. In addition to the $\mathrm{KH} 2$ from FMR1 indicated in the figure, the corresponding region from FXR1 (compare with A) was also prepared.

prediction based on the multiple alignment shows high propensity for secondary structure element formation with helical predominance. These observations suggest that the $\mathrm{N}$-terminal 200 residues of FMR proteins should be folded into a globular domain either autonomously or together with other regions. Two tandem copies of the $\mathrm{KH}$ motif are observed directly following. Sequence homology of the $\mathrm{KH}$ domains within the family is very high ( $80 \%$ identity and $90 \%$ similarity) but, as noticed elsewhere, there is an insertion 70 amino acids long between residue 330 and residue 396 in FMR1 as compared to FXR1 and FXR2 (Siomi et al., 1995; Musco et al., 1996). This insertion was mapped in the $\mathrm{KH} 1$ structure as being expected in a loop between the second and third $\beta$-strand of the $\beta$-sheet (Musco et al., 1996, 1997).

The short consensus sequences GXXG (where $X$ stands for any amino acid) suggested to be involved in the interaction with the RNA is conserved in all the $\mathrm{KH}$ domains. The region directly adjacent to the $\mathrm{C}$-terminus of $\mathrm{KH} 2$ (that corresponds to exon 14) is differentially spliced and will therefore not be present in some of the isoforms (Sittler et al., 1996). However, this region is very well conserved. In the $\mathrm{C}$-terminus, from residue 445 to 625 , conservation breaks down completely. However, although nonconserved, the C-terminus contains copies of an RGG box and is rich in positively charged stretches of arginines and in small hydrophilic residues. In this region, the amino acid composition of all the proteins in the family is not typical of globular domains (37\% charged residues, only $8 \%$ bulky hydrophobic residues, and $34 \%$ small amino acids, which should be compared with the average occurrence of $25 \%$ charged residues, $23 \%$ hydrophobic, and $28 \%$ small amino acids) (Creighton, 1993). Secondary structure predictions support absence of regular secondary structure, thereby suggesting that this region, at least in the absence of a ligand, should be unfolded in solution. The very last seven C-terminal amino acids are again highly conserved.

On the basis of this analysis we designed a number of constructs that should contain the minimal length potentially necessary to retain the main structural features of the full-length protein (Fig. 2B). The potential domain boundaries were defined by conserved patterns and used either alone or in combination to understand the structure-function relationship of these regions.

\section{Do the different regions fold when produced as isolated domains? A structural analysis}

The folding status of the recombinant fragments was analyzed by circular dichroism (CD), a technique that provides overall indication about the secondary structure, and by NMR spectroscopies, which provide detailed information along the sequence. The FNT construct shows a CD spectrum typical of a predominantly $\alpha$-helix structure even though its NMR spectrum has very broad signals and low dispersion suggestive of severe aggregation of the sample (Fig. 3). Analytical gel-filtration chromatography by fast pressure liquid chromatography (FPLC) was performed to probe protein aggregation. The experiment was performed immediately after purification and repeated on the same sample after three months. As noticeable in Figure 3 the chromatograms show the presence of a unique species for the freshly prepared protein but aggregation after three months. These results suggest that the FNT construct is at least partially folded and monodispersed at high dilutions but aggregates at relatively high concentrations. Whether the region forms only secondary structure elements or a proper three-dimensional globular fold remains to be demonstrated.

The construct of $\mathrm{KH} 1$ used for the present studies is the same one for which the three-dimensional structure has previously been reported (Musco et al., 1997). Since the three-dimensional structure of the construct is known, the state of folding of this construct is clearly defined. A construct containing both the $\mathrm{KH} 1$ and the FNT provides a CD spectrum with a signal that corresponds to a helical content approximately additive for the two components (Fig. 4). This is what should be expected if, in the double construct, the secondary structure of each component was not detectably perturbed.

The results obtained for $\mathrm{KH} 2$ are interesting but puzzling; in contrast to the $\mathrm{KH} 1$, a construct containing the KH motif as defined in Musco et al. (1996) resulted in an unfolded protein, as observed both by $C D$ and by 
A

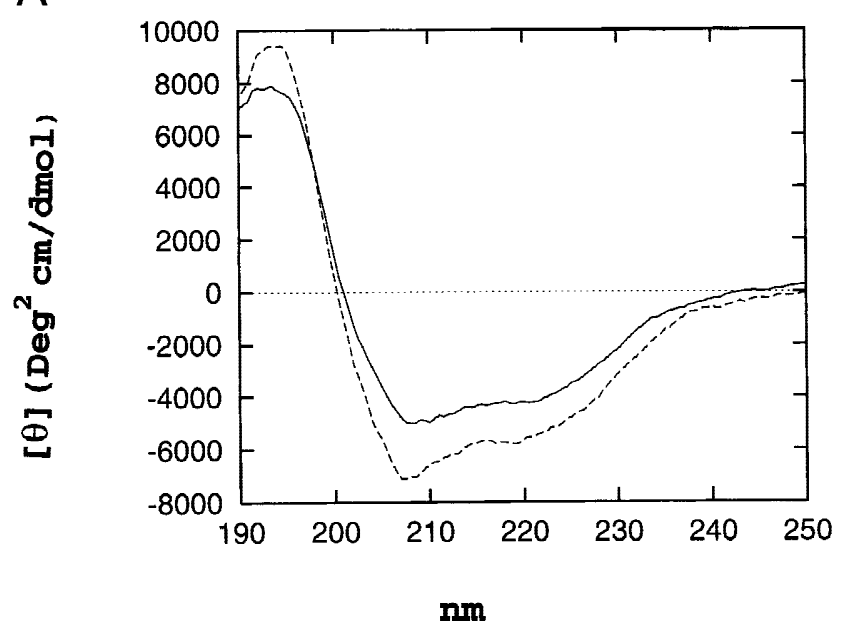

B

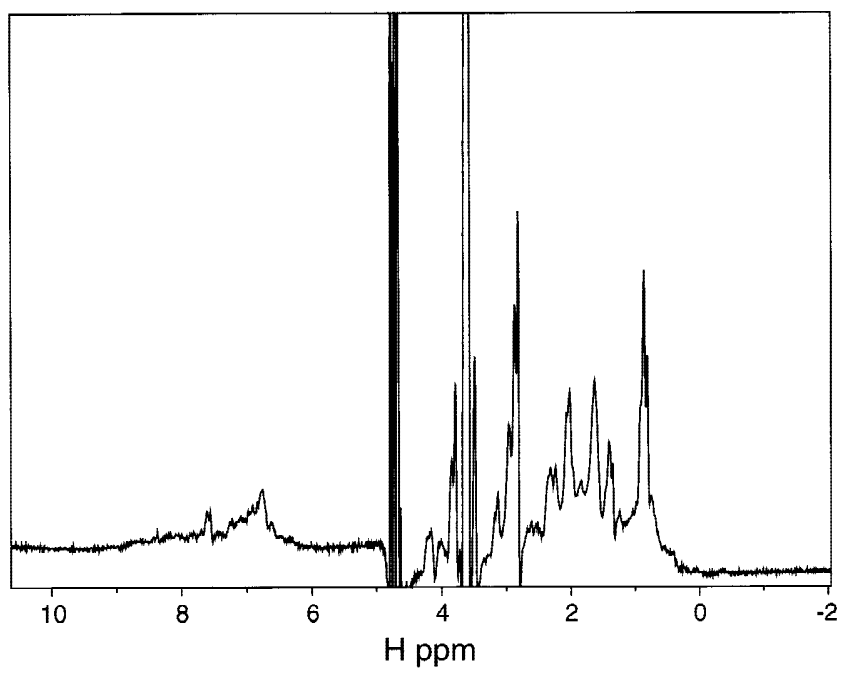

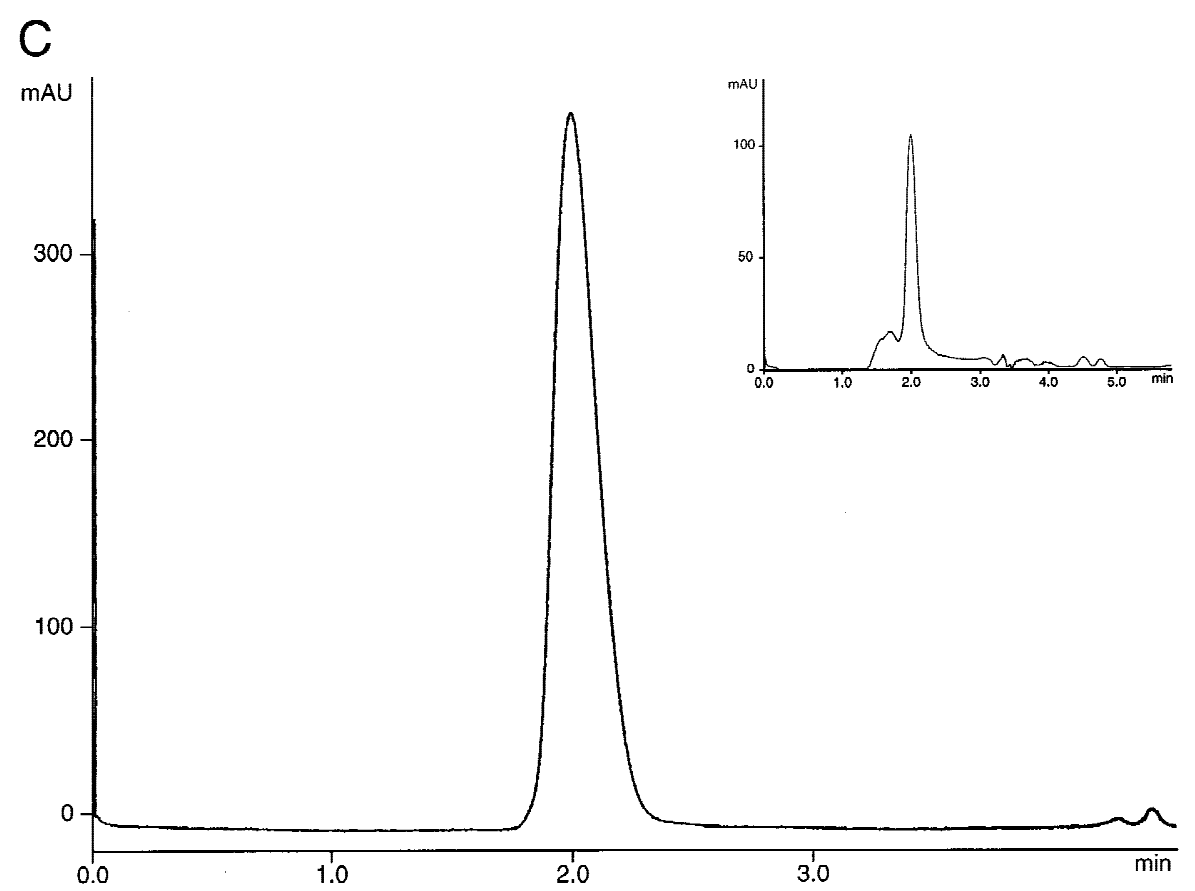

FIGURE 3. Structural data collected for the FNT region. A: Comparison of the Far-UV CD spectra of FNT (continuous line) and the FNT-KH1 (dashed line) construct. The data were recorded at $27^{\circ} \mathrm{C}$ and normalized for the concentration. B: One-dimensional ${ }^{1} \mathrm{H}$-NMR spectrum of the FNT recorded at $600 \mathrm{MHz}$ using $0.5 \mathrm{mM}$ concentration at $27^{\circ} \mathrm{C}$. C: Gel filtration of $1 \mathrm{mg}$ of freshly purified FNT construct. The same profile collected for the protein after three months is shown in the inset.

NMR. In the far-UV CD spectrum, the two expected helical peaks at 208 and $222 \mathrm{~nm}$ collapse into a single minimum shifted at $200 \mathrm{~nm}$ (Fig. 4A). The onedimensional $1 \mathrm{H}$ spectrum is typical of an unfolded and monomeric peptide with very little resonance dispersion (Fig. 4B). To explain this result, we then reasoned that the long insertion present in a loop of $\mathrm{KH} 2$ (Musco et al., 1997) might interfere with correct folding of the domain. To test this hypothesis, $\mathrm{KH} 2$ of FXR1 was produced and characterized with the same techniques. Unfortunately the new construct also showed the same features. Alternatively, another possible explanation is that the presence of flanking regions $(\mathrm{KH} 1$ and/or the exon 14) is necessary to stabilize the $\mathrm{KH} 2$ fold. Two constructs, one with both $\mathrm{KH}$ domains in tandem and another with $\mathrm{KH} 2$ followed by exon 14 (from residue 423 to 446), were prepared. CD and NMR spectra showed conclusively that only $\mathrm{KH} 1$ is folded in the $\mathrm{KH} 1-\mathrm{KH} 2$ construct, whereas $\mathrm{KH} 2$-exon 14 is unfolded (Fig. 4A). From these findings we must conclude that $\mathrm{KH} 2$, as defined by the multiple alignment, does not behave as an independently folded unit. 
A

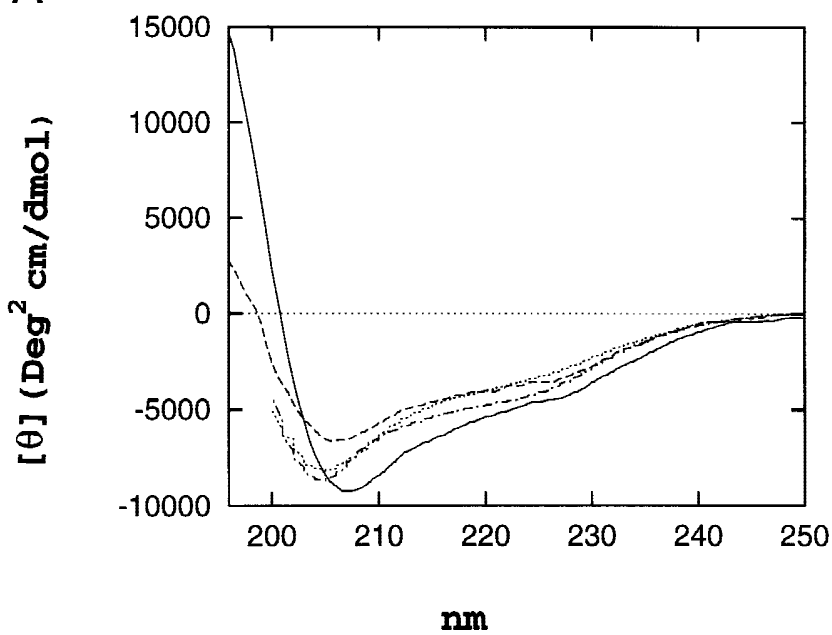

FIGURE 4. Structural data collected for the KH domains. A: Comparison of the Far-UV CD spectra of $\mathrm{KH} 1$ (continuous line), $\mathrm{KH} 2$ (dotted and dashed line), $\mathrm{KH} 2-$ exon 14 (dotted line), and $\mathrm{KH} 1-\mathrm{KH} 2$ (dashed line). The spectra were all collected at room temperature. B: Expansion of a one-dimensional ${ }^{1} \mathrm{H}-\mathrm{NMR}$ spectrum of the $\mathrm{KH} 2-$ exon 14 construct and comparison with the spectrum of $\mathrm{KH} 1$. While the resonances of $\mathrm{KH} 1$ are nicely dispersed in a larger spectral range, the spectrum of $\mathrm{KH} 2$-exon 14 is typical of an unfolded species.

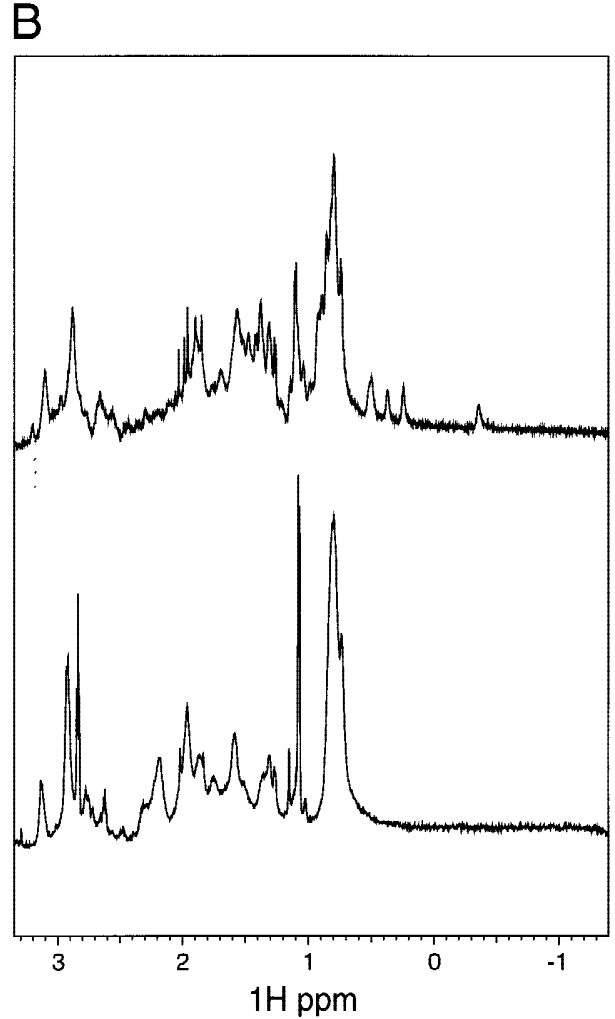

Finally, the FCT was tested. Its CD spectrum consists of a single minimum around $200 \mathrm{~nm}$ (Fig. 5), characteristic of an unfolded state. Titration of the solution with heparin, a poly-anion typically used to mimic the effect of DNA/RNA binding and to estimate the effect of a highly charged species to promote folding, did not lead to significant changes of the spectrum.

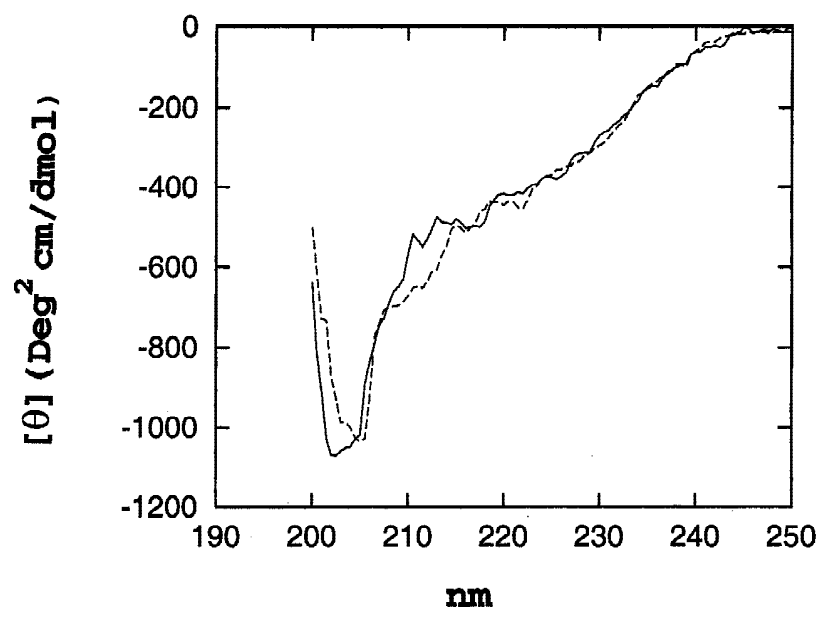

FIGURE 5. Far-UV spectra of the FCT construct recorded at room temperature and $10 \mu \mathrm{M}$ protein concentration. The sample was titrated with heparin up to a protein:heparin ratio of 1:5. The dashed line represents the last point of the titration. No changes in the spectrum appearance were detected.
The constructs were then used for testing their RNAbinding properties.

\section{Do isolated domains bind to RNA? RNA-binding assays}

The different protein constructs shown in Figure $2 \mathrm{~b}$ were assayed for RNA-binding activity using RNA homopolymers immobilized on agarose beads. The results of the binding assays are shown in Figure 6A; all the constructs bind to RNA homopolymers at $150 \mathrm{mM}$ $\mathrm{NaCl}$ concentration. When the constructs were assayed in the absence of agarose beads, no signal was detected. To test possible interference of the His-tag tail in the binding, the assay was repeated using as a blank an His-tagged protein that is known not to bind to RNA (cysteine string protein, kindly provided by Prof. Benefenati, Rome). No signal was detected using the specific anti-His-tag antibody. Interestingly, only $\mathrm{KH} 1$ binds to RNA, whereas $\mathrm{KH} 2$ does not, even after overnight incubation. Our results also provide the first direct evidence that shows binding of the RGG box and, rather unexpectedly, of the protein $\mathrm{N}$-terminal domain. To rule out any possible doubt about interference of the Histag on the binding, the FNT was produced also as fusion protein with glutathione-S-transferase (GST), cleaved from this and assayed for RNA binding. Comparison of the binding observed for the two constructs 
A

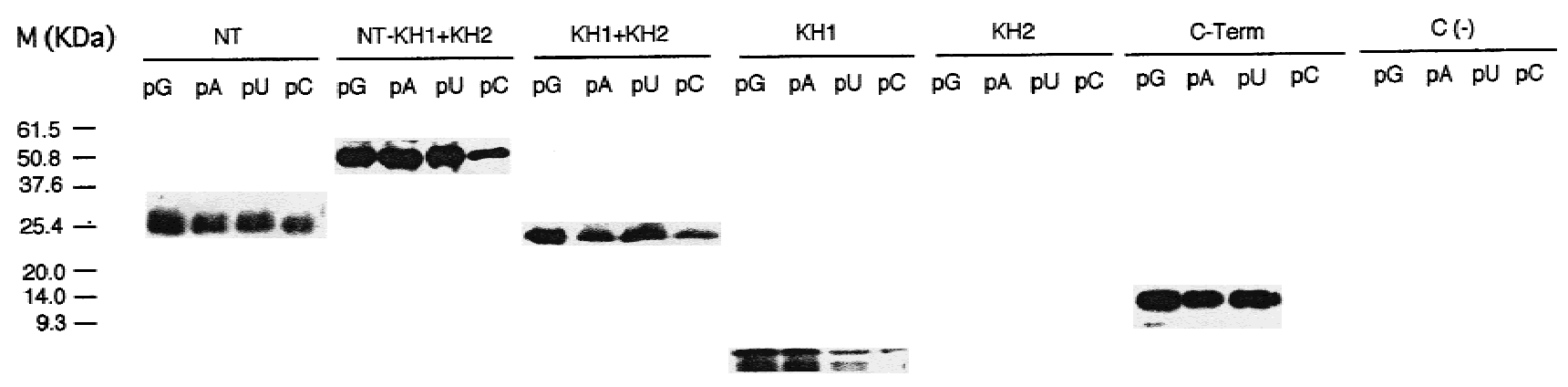

B

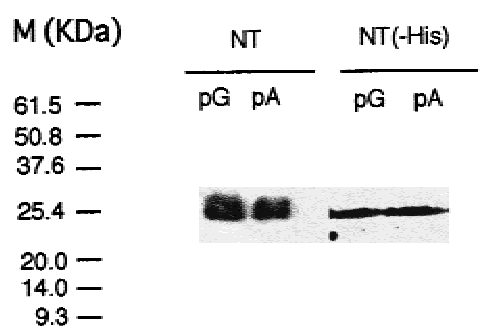

FIGURE 6. RNA-binding assays using RNA homopolymers immobilized on agarose beads. A: Comparison of the assay performed at $\mathrm{pH} 7.5$ and $150 \mathrm{mM} \mathrm{NaCl}$ concentration as indicated in Materials and Methods for the most significant constructs. B: Comparison of the assay performed for the FNT construct with and without the His-tag. The His-tagged construct was revealed on the gel using an anti-His-tag antibody, whereas the construct without His-tag was revealed by a anti-N-terminus monoclonal antibody. Each picture is the summary of at least three independent observations recorded in different periods and with different protein batches.

is shown in Figure 6B. The constructs show comparable behavior (Fig. 6B).

In terms of nucleotide specificities, the different constructs have different polynucleotide preferences: most of them are purine preferring. The binding of the FCT domain is so strong that it shows comparable affinity for poly-(rA), ( $r G)$ and $(r U)$. To test the contribution of aspecific binding due to electrostatic interactions, the assay was repeated at increasing ionic strength varying from $150 \mathrm{mM}$ to $500 \mathrm{mM} \mathrm{NaCl}$ concentration. The fragments exhibit decreasing binding to RNA homopolymers. The FNT completely loses its capability to bind to RNA, whereas the FCT retains a weaker affinity for purine homopolymers (data not shown).

\section{DISCUSSION}

We have presented here data that characterize the RNA-binding properties of FMR1. In the absence of any known specific FMR1-RNA sequence, RNA homopolymers were used to detect differential specificities along the sequence. In our study, we have taken advantage of the commonly used approach of producing deletion mutants, but have complemented it with a characterization of the folding state of the fragments tested for RNA binding. This step is essential for correct interpretation of the binding assays: it is the only way to understand whether an isolated protein fragment retains a tertiary structure arrangement similar to that adopted in the full-length protein and therefore if deletion of a given region has a structural rather than a functional effect. Several deletion mutants of the fulllength FMR1 protein were produced, purified, and probed for RNA-binding. Selection of the construct boundaries was made according to a semirational approach based on detailed inspection of the protein sequence and identification of regions conserved among all members of the FMR family.

Several lines of evidence suggest that the whole $\mathrm{N}$-terminal region of FMR1 up to exon 14 is able to adopt a well-defined tertiary structure: the amino acid distribution is that typical of folded domains, the whole block is strongly conserved in the family, and conservation comprises residues that should be able to form the hydrophobic core of the protein. Within this region, however, only $\mathrm{KH} 1$ was proven to form a globular fold when produced as an isolated fragment. For the FNT construct, we have indications of secondary structure, but not directly of a tertiary fold. Because it tends to aggregate, it is likely that, without other regions of the 
protein, a number of hydrophobic residues are exposed in the isolated fragment. This observation might have important implications for interpreting the previously reported interaction between FMR1 and its homologs mapped in a stretch 40 amino acids long between residue 171 and 211 (Siomi et al., 1996). The results described by Siomi et al. might also be explained either by an artefactual competition between homo- and heteroaggregates or by deletion of residues important for the fold but not directly involved in the recognition. Only further experiments and a structural characterization of the complex will resolve this point.

$\mathrm{KH} 2$ does not form a globular domain, even when produced with its flanking regions. This is somewhat surprising because the sequence similarity with $\mathrm{KH} 1$ would strongly suggest that the two motifs behave similarly and form independently stable globular domains. However, identification of domain boundaries in proteins is not an easy task and there are examples in the literature in which the same motif in different proteins needs different regions to fold as a stable domain (e.g., Macias et al., 1996). Our results could be explained by the necessity of other partners of the RNP complexes such as FXR1 and FXR2 to stabilize the KH2 fold or, more likely, by the necessity of a spatial arrangement that in the full-length protein brings together $\mathrm{KH} 2$ and other nonsequential regions of the protein (e.g., FNT). The data accumulated on the FCT confirm that the region is nonglobular as expected from the large number of positively charged residues and glycines.

Although binding of FMR1 to RNA homoribonucleotides has been reported before (Siomi et al., 1993a; Dejgaard \& Leffers, 1996), we have shown for the first time that purified domains of FMR1 bind directly to RNA with different specificities. Novel RNA-binding motifs were characterized at the two ends of the protein, both in the FNT region in which no previously recognized RNA-binding motif could be identified a priori, and in the arginine-rich FCT. In our binding assays, FNT with and without His-tag binds RNA with purine preference (such preference becomes more evident at short exposure times). Binding increases for the construct with the FNT coexpressed with $\mathrm{KH} 1$. Binding of $\mathrm{KH} 1$ but not of $\mathrm{KH} 2$ strongly suggests that correct threedimensional arrangement is essential for this sequence motif. The binding of $\mathrm{KH} 1$ shows homopurine preference in agreement with data previously reported by Dejgaard and Leffers (1996) for a construct containing $\mathrm{KH} 1$ and a truncated $\mathrm{KH} 2$. It should be noted that $\mathrm{KH}$ domains from different proteins have been described to have different specificities, with a preference for poly(rG) (Siomi et al., 1993a; Leffers et al., 1995; Dejgaard \& Leffers, 1996; Buckanovich \& Darnell, 1997). Finally, the FCT region binds very strongly and almost without nucleotide specificity. It is reasonable to predict that the interaction with nucleic acids will, in this region, be mostly electrostatic according to the induced fit mechanism observed in some other protein/nucleic acid complexes (Puglisi et al., 1995; Markus et al., 1997). These observations support the hypothesis that, while the whole region of FMR1 up to exon 14 provides specific sequence recognition, the FCT acts as an aspecific anchoring surface.

At high ionic strength, binding of polynucleotides is weakened for the FCT but disappears completely for the other constructs (data not shown). Binding was also found to disappear above $500 \mathrm{mM}$ salt for the fulllength FMR1 protein (Siomi et al., 1993a). Although these results may look contradictory at first (it is expected that only specific binding is retained at high ionic strength), it must be considered that, in the absence of the specific RNA sequence, we are forced to probe binding with nucleotide homopolymers. It is therefore plausible that binding will be destabilized more for regions that would need a specific sequence to bind than for highly charged stretches for which electrostatic forces are the main driving force. Different regions of the protein seem to modulate the specificity mutually so that the overall behavior is not simply additive. The full-length FMR1 has been previously reported to bind to poly-(rG) but also, to a minor extent, poly-(rU) (Siomi et al., 1993a), which we do not observe. Binding of the $\mathrm{KH} 1-\mathrm{KH} 2$ construct seems less specific than that of the $\mathrm{KH} 1$ alone. This could suggest that, even if not capable of binding when isolated, $\mathrm{KH} 2$ can provide some contribution in the context of the double construct.

Demonstrating that both the $\mathrm{N}$ - and the $\mathrm{C}$-terminus of the protein are able to bind to RNA has important consequences for understanding the functions of FMR1 in the cell. FMR1 has been proposed to be involved in the shuttling of RNAs from the nucleus to the cytoplasm as well as with actively translating polysomes (Eberhart et al., 1996; Kandjian et al., 1996; Corbin et al., 1997; Feng et al., 1997). Eberhart et al. (1996) have suggested a model for FMR1 in which the native cytoplasmatic protein enters the nucleus transported by a yet unknown NLS-binding carrier. In the nucleus, FMR1 would assemble into an mRNP particle, interacting with specific mRNA transcripts. Once formed, the mRNP particle would be exported to the cytoplasm where it would associate with translating polysomes. In the cytoplasm, FMR1 would bind to specific transcripts and possibly influence translation. Shuttling functions have been proposed also for other $\mathrm{KH}$ containing proteins such as vigilin (Engebrecht \& Roeder, 1990; Siomi et al., 1993b; Kuegler et al., 1996; Kruse et al., 1998). Export through the nuclear pore of RNP complexes has been shown for several NLS-containing proteins (Nakielny \& Dreyfuss, 1997; Nakielny et al., 1997; Mattaj \& Englmeier, 1998). Deletion data by Mandel and coworkers conclusively demonstrate that both the $\mathrm{N}$ and the C-termini of FMRP are involved in the interaction with polysomes and that this is independent of the presence of FXR1 and FXR2, thus excluding a 
mediation of these two proteins (Bardoni \& Mandel, in prep.). On the basis of our data we can expand the model by Eberhart et al. (1996) suggesting a more detailed description of the events involved. The capacity of the FNT to bind to RNA directly as demonstrated in the present work strongly suggests a mechanism of competition between the RNA binding site and the NLS, both localized in the same region of the protein. Once in the nucleus, the protein would bind to an mRNA and other proteins and form a mRNP (in agreement with Corbin et al., 1997). The role of the $\mathrm{KH}$ domains in the interaction would be to confer specificity to RNA recognition, whereas the RGG box would increase affinity. As a consequence of the complex formation, the NLS present in the $\mathrm{N}$-terminus would be masked, leading to export of the complex to the cytoplasm. Here, the complex would transport the RNA to the polysomes where binding would mostly occur via RNA (Corbin et al., 1997; Feng et al., 1997). A higher binding affinity of the RNA with the polysome would then result in the disassembly of the RNA/FMR1 complex with the consequent release of the protein into the cytoplasm, completing the cycle of FMR1 in its suggested role as RNA carrier.

\section{MATERIALS AND METHODS}

\section{Sequence analysis}

The sequences were retrieved from the Swiss-Prot database using the sequence retrieval server (SRS). A multiple alignment was obtained with the CLUSTALX program (Thompson et al., 1997) and, when necessary, edited using the GDE program. Secondary structure prediction was obtained by the PHD program (Rost \& Sander, 1993) using the multiple alignment previously obtained as input.

\section{Sample production}

The DNA sequences coding for all the FMR1 fragments analyzed were PCR amplified with engineered $\mathrm{Ncol}$ on $5^{\prime}$ ends and $\mathrm{BamHI}$ or Notl on $3^{\prime}$ ends. The constructs were cloned into a pET9-derived plasmid vector following the encoding histidine tag (MSHHHHHHSM), which was included for purification purposes and not removed. The constructs were expressed in Escherichia coli strain BL21 (DE3) and the proteins were induced for $3 \mathrm{~h}$ in $8 \mathrm{~L}$ LB medium with Ampicillin $100 \mathrm{mg} / \mathrm{L}$ by addition of $0.2 \mathrm{mM}$ isopropyl b-D-thiogalactopyranoside (IPTG) after the cultures had reached an optical density (OD) of 0.8 at $600 \mathrm{~nm}$. The cells were spun down $(5,000 \mathrm{rpm})$ in a Beckman centrifuge (model J2-21) with a JA10 rotor. The pellets were suspended with $200 \mathrm{~mL}$ of Tris$\mathrm{HCl}$ buffer $20 \mathrm{mM}, \mathrm{pH} 8, \mathrm{NaCl} 300 \mathrm{mM}, 0.2 \%$ Nonidet P40, $2 \mathrm{mM} \beta$-mercaptoethanol. To the lysis buffer were added Pefabloc (Boehringer Mannheim) as antiproteases, DNase I (Boehringer Mannheim), and lysozyme (Sigma). Cells were lysed by ultra-sonication (Branson sonifier, model 250/450), for $5 \mathrm{~min}$ at amplitude 5 . The lysate was ultra-centrifuged in a Beckman centrifuge (model I-70) with Ti-45 rotor for $1 \mathrm{~h}$ at
$40,000 \mathrm{rpm}$ at $4^{\circ} \mathrm{C}$. The proteins were purified by Ni-NTA column (Qiagen) chromatography. The elution was carried out in two steps: $50 \mathrm{~mL}$ of $50 \mathrm{mM}$ imidazol and $50 \mathrm{~mL}$ of $300 \mathrm{mM}$ imidazol in a standard lysis buffer. The protein solutions were dialyzed against $20 \mathrm{mM}$ Tris- $\mathrm{HCl}$ buffer with $100 \mathrm{mM} \mathrm{NaCl}$ at pH 8, concentrated with Amicon concentrator (model 8050) and loaded on superdex 16/60 high load gel-filtration column equilibrated with $20 \mathrm{mM}$ Tris- $\mathrm{HCl}$, $500 \mathrm{mM} \mathrm{NaCl}, 2 \mathrm{mM} \beta$-mercaptoethanol at pH 8. The fractions that contained the pure protein were pooled together and stored at $4{ }^{\circ} \mathrm{C}$. The $\mathrm{N}$-terminus tagless was obtained cloning the fragment PCR amplified with engineered $\mathrm{Ncol}$ on $5^{\prime}$ and Notl on $3^{\prime}$ ends into a pET9-derived plasmid vector following the encoding histidine tag and GST. For each fragment, more than one preparation produced samples to allow comparison and ensure data reproducibility.

Gel filtration to detect aggregation was performed on HiLoad column 10/30 Superdex 75 (Pharmacia Biotec) loading $1 \mathrm{mg}$ of protein.

\section{Circular dichroism}

CD measurements were performed on a Jasco J-710 spectropolarimeter equipped with a thermostatically controlled cell holder stabilized by circulating water from a Neslab RTE- 110 water bath. A rectangular quartz thermostated cuvette with $0.1 \mathrm{~cm}$ pathlength was used (Hellma). All the spectra were baseline corrected by subtracting buffer spectra and the observed ellipticity was then converted to mean residue weight ellipticity $[\theta] /\left(\right.$ degree $\left.\cdot \mathrm{cm}^{2} \cdot \mathrm{dmol}^{-1}\right)$. The protein concentration was determined by measuring the dilution into $6 \mathrm{M}$ guanidine hydrochloride of a concentrated protein stock solution ( $1 \mathrm{mM}$ ) assuming tyrosine absorbance at $276 \mathrm{~nm}$. An extinction coefficient of $1450 \mathrm{M}^{-1} \cdot \mathrm{cm}^{-1}$ and of $145 \mathrm{M}^{-1}$. $\mathrm{cm}^{-1}$ as reported for Gly-L-Tyr-Gly at $276 \mathrm{~nm}$ and for GlyL-Cys-Gly at $276 \mathrm{~nm}$ respectively was used. The protein concentrations were $5 \mu \mathrm{M}, 17 \mu \mathrm{M}$, and $10 \mu \mathrm{M}$ for the FNT, KH1, and FCT, respectively. CD spectra were averaged over five scans obtained by collecting data at $0.5-\mathrm{nm}$ intervals from 250-190 nm. The temperature-dependent folding and unfolding were followed, monitoring the ellipticity at $215 \mathrm{~nm}$ from 4 to $73^{\circ} \mathrm{C}$ at a heating rate of $20^{\circ} \mathrm{C} / \mathrm{h}$.

\section{NMR measurements}

The NMR experiments were performed on a UNITY VARIAN $600 \mathrm{MHz}$ spectrometer equipped with z-shielded gradient coils using $0.5-1.0 \mathrm{mM}$ samples in $90 \% \mathrm{H}_{2} \mathrm{O} / 10 \% \mathrm{D}_{2} \mathrm{O}$. The experiments were performed at $27^{\circ} \mathrm{C}$.

\section{RNA-binding assay}

Binding of His-tagged fusion mutant proteins to RNA homopolymers was carried out as described in Swanson and Dreyfuss (1988) with minor modifications. Agarose-bound polyribonucleotide-binding reactions were carried out with $3 \mu \mathrm{g}$ of different purified protein constructs in a total volume of $0.5 \mathrm{~mL}$ of binding buffer (10 mM Tris, $\mathrm{pH} 7.4,2.5 \mathrm{mM}$ $\mathrm{MgCl}_{2}, 0.5 \%$ Triton, 150 or $500 \mathrm{mM} \mathrm{NaCl}$ ) for $20 \mathrm{~min}$ at $40^{\circ} \mathrm{C}$. The beads were pelleted with a brief spin in a microfuge and washed three times with binding buffer prior to resuspension 
in SDS-PAGE loading buffer. Bound proteins were eluted from the nucleic acid by boiling and resolved on a SDSpolyacrylamide gel and visualized by immunoblot.

\section{Western blot analysis}

Proteins were resolved on an SDS-polyacrylamide gel and transferred to PVDF membrane (Amersham). Filters were processed according to the instructions of the manufacturer and probed with either the anti His-tag antibody (Sigma) or a polyclonal anti-FMR1 antibody or a mouse monoclonal raised against the amino-terminal domain (courtesy of J.L. Mandel and B. Bardoni).

\section{ACKNOWLEDGMENTS}

We are strongly indebted to Barbara Bardoni and Jean-Louis Mandel for constant exchange of information and for donating the antibodies used in the present work.

Received March 19, 1999; returned for revision April 16, 1999; revised manuscript received May 25, 1999

\section{REFERENCES}

Abitbol M, Menini C, Delezoide AL, Rhyner T, Vekemans M, Mallet J. 1993. Nucleus basalis magnocellularis and hippocampus are the major sites of FMR1 expression in the brain. Nature Genet 4:147152.

Bardoni B, Sittler A, Shen Y, Mandel JL. 1997. Analysis of domains affecting intracellular localization of the FMRP protein. Neurobio Dis 4:329-336.

Brown V, Small K, Lakkis L, Feng Y, Gunter C, Wilkinson KD, Warren ST. 1998. Purified recombinant Fmrp exhibits selective RNA binding as an intrinsic property of the fragile $X$ mental retardation protein. J Biol Chem 273:15521-15527.

Buckanovich RJ, Darnell RB. 1997. The neuronal RNA binding protein Nova-1 recognizes specific RNA targets in vitro and in vivo. Mol Cell Biol 17:3194-3201.

Corbin F, Bouillon M, Fortin A, Morin S, Rousseau F, Khandjian EW. 1997. The fragile $X$ mental retardation protein is associated with poly $(\mathrm{A})+$ mRNA in actively translating polyribosomes. Hum Mol Genet 6:1465-1472.

Creighton TE. 1993. Proteins. New York: WH Freeman and Company.

De Boulle K, Ververk AJMH, Reyniers E, Vits L, Hendrickx J, Van Roy B, VanDenBos F, de Graaff E, Oostra BA, Willems PJA. 1993. Point mutation in the FMR1 gene associated with fragile $X$ mental retardation. Nature Genet 3:31-35.

Dejgaard K, Leffers H. 1996. Characterization of the nucleic acid binding activity of $\mathrm{KH}$ domains: Different properties of different domains. Eur J Biochem 241:425-431.

Devys D, Lutz Y, Rouyer N, Bellocq JP, Mandel JL. 1993. The FMR1 protein is cytoplasmic, most abundant in neurons and appears normal in carriers of a fragile X premutation. Nature Genet 4:335340.

Eberhart DE, Malter HE, Feng, Y, Warren ST. 1996. The fragile $X$ mental retardation protein is a ribonucleoprotein containing both nuclear localization and nuclear export signals. Hum Mol Genet 5:1083-1091.

Engebrecht J, Roeder GS. 1990. MER1, a yeast gene required for chromosome pairing and genetic recombination, is induced in meiosis. Mol Cell Biol 10:2379-2389.

Feng Y, Absher D, Eberhart DE, Brown V, Malter HE, Warren ST. 1997. FMRP associates with polyribosomes as an mRNP, and the I304N mutation of severe fragile $X$ syndrome abolishes this association. Mol Cell 1:109-118.

Fridell RA, Benson RE, Hua J, Bogerd HP, Cullen BR. 1996. A nuclear role for the fragile $\mathrm{X}$ mental retardation protein. EMBO $\mathrm{J}$ 15:5408-5414.
Gibson TJ, Thompson JD, Heringa J. 1993. The KH domain occurs in a diverse set of RNA-binding proteins that include the antiterminator NusA and is probably involved in binding to nucleic acid. FEBS Lett 3:361-366.

Hagerman RJ. 1991. Physical and behavioral phenotype. In: Hagerman RJ, Silverman AC, eds. Fragile X syndrome: Diagnosis, treatment and research. Baltimore, Maryland: Johns Hopkins University Press. pp 3-88.

Imbert G, Feng Y, Nelson DL, Warren ST, Mandel JL. 1998. FMR1 and mutations in fragile X syndrome: Molecular biology, biochemistry and genetics. In: Warren ST, Wells RD, eds. Genetic instabilities and hereditary neurological diseases. New York: Academic Press. pp 27-53.

Kanamori H, Dodson RE, Shapiro DJ. 1998. In vitro genetic analysis of the RNA binding site of vigilin, a multi-KH-domain protein. Mol Cell Biol 18:3991-4003.

Kandjian E, Corbin F, Woerly S, Rousseau F. 1996. The fragile X mental retardation protein is associated with ribosomes. Nature Genet 12:91-93.

Kruse C, Gruenweller A, Willkimm DK, Pfeiffer T, Hartmann RK, Mueller PK. 1998. tRNA is entrapped in similar, but distinct, nuclear and cytoplasmic ribonuclear complexes, both of which contain vigilin and elongation factor $1 \alpha$. Biochem $J$ 329:615-621.

Kuegler S, Gruenweller A, Probst C, Klinger M, Mueller PK, Kruse C. (1996). Vigilin contains a functional nuclear localization sequence and is present in both cytoplasm and the nucleus. FEBS Lett 382:330-334.

Leffers H, Dejgaard K, Celis JE. 1995. Characterization of two major cellular poly $(\mathrm{rC})$-binding human proteins each containing three K-homologous (KH) domains. Eur J Biochem 230:447-453.

Macias MJ, Hyvonen M, Baraldi E, Schultz J, Sudol M, Saraste M, Oschkinat H. 1996. Structure of the WW domain of a kinaseassociated protein complexed with a proline-rich peptide. Nature 382:646-649.

Mandel JL, Heitz D. 1992. Molecular genetics of the fragile X syndrome: A novel type of unstable mutation. Curr Opin Gen Dev 2:422-430.

Markus MA, Hinck AP, Huang S, Draper DE, Torchia DA. 1997. High resolution structure of ribosomal protein L11-C76, a helical protein with a flexible loop that becomes structured upon binding to RNA. Nature Struc Biol 4:70-76.

Mattaj IW, Englmeier L. 1998. Nucleocytoplasmic transport: The soluble phase. Annu Rev Biochem 67:265-306.

Musco G, Kharrat A, Stier S, Fraternali F, Gibson TJ, Nilges M, Pastore A. 1997. The solution structure of the first KH domain of FMR1, the protein responsible for fragile $X$ syndrome. Nature Struc Biol 4:712-716.

Musco G, Stier G, Joseph C, Castiglione Morelli MA, Nilges M, Gibson TJ, Pastore A. 1996. Three-dimensional structure and stability of the $\mathrm{KH}$ domain: Molecular insights into the fragile $\mathrm{X}$ syndrome. Cell 85:237-245.

Nakielny S, Dreyfuss G. 1997. Nuclear export of proteins and RNAs. Curr Opin Cell Biol 9:420-429.

Nakielny S, Fischer U, Michael WM, Dreyfuss G. 1997. RNA transport. Annu Rev Neurosci 20:269-301.

Pieretti M, Zhang F, Fu YH, Warren ST, Oostra BA, Caskey CT, Nelson DL. 1991. Absence of expression of the FMR1 gene in fragile X syndrome. Cell 66:817-822.

Puglisi JD, Chen L, Blanchard S, Frankel AD. 1995. Solution structure of a bovine immunodeficiency virus tat-TAR peptide-RNA complex. Science 270:1200-1203.

Rost B, Sander C. 1993. Improved prediction of protein secondary structure by use of sequence profiles and neural networks. Proc Natl Am Soc 90:7558-7562.

Siomi H, Choi MC, Siomi MC, Nussbaum RL, Dreyfuss G. 1994. Essential role for $\mathrm{KH}$ domains in RNA binding: Impaired RNA binding by a mutation in the $\mathrm{KH}$ domain of FMR1 that causes fragile $X$ syndrome. Cell 77:33-39.

Siomi H, Matunis MJ, Michael WM, Dreyfuss G. 1993b. The premRNA binding $\mathrm{K}$ protein contains a novel evolutionarily conserved motif. Nucleic Acids Res 21:1193-1198.

Siomi H, Siomi MC, Choi MC, Nussbaum RL, Dreyfuss G. 1993a. The protein product of the fragile X gene, FMR1, has characteristics of an RNA-binding protein. Cell 74:1193-1198.

Siomi MC, Siomi H, Sauer WH, Srinivisan S, Nussbaum RL, Drey- 
fuss G. 1995. FXR1, an autosomal homolog of the fragile X mental retardation gene. EMBO J 14:2401-2408.

Siomi MC, Zhang Y, Siomi H, Dreyfuss G. 1996. Specific sequences in the fragile $X$ syndrome protein FMR1 and FXR proteins mediate their binding to $60 \mathrm{~S}$ ribosomal subunits and the interactions among them. Mol Cell Biol 16:3825-3832.

Sittler A, Devys D, Weber S, Mandel JL. 1996. Alternative splicing of exon 14 determines nuclear or cytoplasmic localization of FMR1 protein isoforms. Hum Mol Genet 5:95-102.

Swanson MS, Dreyfuss G. 1988. Classification and purification of proteins of heterogeneous nuclear ribonucleoprotein particles by RNA-binding specificities. Mol Cell Biol 5:2237-2241.

Thompson JD, Gibson TJ, Plewniak F, Jeanmougin F, Higgins DG. 1997. The CLUSTALX windows interface: Flexible strategies for multiple sequence alignment aided by quality analysis tools. $\mathrm{Nu}$ cleic Acids Res 25:4876-4882.
Urlaub H, Kruft V, Bischof O, Mueller EC, Wittmann-Liebold B. 1995. Protein-rRNA binding features and their structural and functional implications in ribosomes as determined by cross-linking studies. EMBO J 14:4578-4588.

Verkerk AJMH, Pierretti M, Sutcliffe JS, Fu YH, Kuhl DPA, Pizzuti A, Reiner O, Richards S, Victoria MF, Zhang F, Eussen BE, van Ommen GJB, Blonden LAJ, Riggins GJ, Chastain JL, Kunst CB, Galijaard H, Caskey CT, Nelson DL, Oostra BA, Warren ST. 1991. Identification of a gene (FMR1) containing a GCC repeat coincident with a breakpoint cluster region exhibiting length variation in fragile X syndrome. Cell 65:905-914.

Yang YYL, Yin GL, Darnell RB. 1998. The neuronal RNA-binding protein nova-2 is implicated as the autoantigen targeted in POMA patients with dementia. Proc Natl Acad Sci USA 95:1325413259. Cell 65:905-914. 